\title{
Development of small interfering RNA delivery system using PEI-PEG-APRPG polymer for antiangiogenic vascular endothelial growth factor tumor-targeted therapy
}

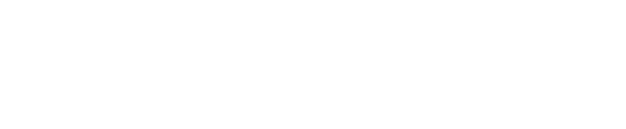

\section{Zong-Xia Lu' \\ Li-Ting Liu ${ }^{1,2}$ \\ Xian-Rong $\mathrm{Qi}^{1}$}

'Department of Pharmaceutics, School of Pharmaceutical Sciences, Peking University, Beijing, People's Republic of China; ${ }^{2}$ Department of Pharmacy, School and Hospital of Stomatology, Peking University, Beijing, People's Republic of China
Correspondence: Xian-Rong Qi

Department of Pharmaceutics, School of Pharmaceutical Sciences, Peking University, 38 Xueyuan Road, Beijing 10019I, People's

Republic of China

Tel +86 I0 $8280 I 584$

Fax $+86 \quad 108280 I 584$

Email qixr200I@yahoo.com.cn
Background: Small interfering RNA (siRNA) can silence target genes in the cytoplasm and be a major tool in gene therapy. Vascular endothelial growth factor (VEGF), a potent regulator of angiogenesis, is overexpressed in most tumors and is closely associated with tumor growth and metastasis. It has been shown that inhibition of VEGF expression by siRNA is an effective and useful method for antiangiogenic tumor therapy.

Methods: In the present study, we synthesized a targeted delivery system of PEI-PEG-APRPG incorporating angiogenic vessel-homing Ala-Pro-Arg-Pro-Gly (APRPG) peptide into cationic polyethylenimine (PEI) via a hydrophilic poly(ethylene glycol) (PEG) spacer.

Results: PEI-PEG-APRPG effectively condensed siRNA into 20-50 nm nanoparticles with a positive surface charge using a suitable N/P ratio. The siRNA/PEI-PEG-APRPG complex effectively enhanced the stability of siRNA in RNase A, and improved the proliferation-inhibiting ability and transfection efficiency of siRNA in vitro and tumor accumulation in vivo. In addition, the siRNA/PEI-PEG-APRPG complex exhibited high efficiency as antitumor therapy with regard to tumor growth, microvessel density, and VEGF protein and mRNA levels.

Conclusion: These findings suggest that PEI-PEG-APRPG effectively delivers siRNA to tumors overexpressing VEGF and thereby inhibits tumor growth.

Keywords: PEI-PEG-APRPG, VEGF siRNA, gene delivery, tumor-targeted, antiangiogenic therapy

\section{Introduction}

Since RNA interference was discovered in Caenorhabditis elegans a decade ago, many researchers worldwide have used this technique to downregulate disease-causing genes in various human diseases, including viral infections, ocular diseases, neurodegenerative disorders, and cancers. ${ }^{1,2}$ RNA interference, a process characterized by sequence-specific, post-transcriptional gene silencing directed by short interfering 21-23 nucleotide double-stranded RNA (siRNA) can specifically and markedly reduce the expression of targeted mRNA. ${ }^{3}$ In siRNA therapeutics, a lot of vectors for siRNA delivery have been reported to achieve perfect results with in vitro applications, but these vectors were mostly inappropriate for use in vivo or are only administered locally. ${ }^{4}$ To be administered systemically, targeted siRNA delivery should be designed to improve accumulation of siRNA at three levels, ie, the target tissue, target cell, and intracellular target site of action. 
Angiogenesis (also known as neovascularization) is defined as the development of new blood vessels from preexisting vessels, and is an attractive target for cancer therapy because it is essential for tumor growth and hematogenous metastasis. ${ }^{5}$ Growth and survival of tumors depends on the tumor vessels being able to supply oxygen and nutrient substances. Tumors can only reach a size of 1-2 $\mathrm{mm}^{3}$ without angiogenesis. ${ }^{6-8}$ Vascular endothelial growth factor (VEGF) is a positive and potent regulator of angiogenesis. ${ }^{9,10}$ Inhibition of VEGF production by siRNA was reported to be an effective and useful method for antiangiogenic tumor therapy in vitro and in vivo. ${ }^{11}$ Additionally, Ala-Pro-ArgPro-Gly (APRPG) peptide was identified as an angiogenic vessel-homing peptide by $\mathrm{Oku}$ et al. ${ }^{12}$ They isolated the APRPG peptide which specifically accumulated at the angiogenic site using a phage-displayed peptide library in an angiogenesis model in mice, suggesting that APRPG is a useful probe for angiogenic vessels, although the target molecule was still unknown. Specifically, APRPG only adhered to neovascular endothelial cells, and not to tumor cells or other normal cells. Doxorubicin, CNDAC (an antitumor nucleoside antimetabolite), and SU1498 (a receptor tyrosine kinase inhibitor of VEGF receptor 2) encapsulated in the APRPG-modified liposomes have achieved a remarkable therapeutic effect in some tumor models, such as colon 26 NL-17 carcinoma and doxorubicin-resistant P388 solid tumor cell lines. ${ }^{13-15}$

siRNA delivery systems include viral and nonviral vectors. Nonviral vectors possess several advantages, including safety and easy modification, but they have lower transfection efficiency than viral vectors. Polyethylenimine (PEI) has a high cationic charge density and can bind and condense siRNA, protecting siRNA against nucleases and reducing renal clearance. siRNA-PEG/PEI polyelectrolyte complexes formulated using poly(ethylene glycol) (PEG) modified siRNA (PEG-siRNA), and PEI has been successfully applied. ${ }^{16}$ In our previous report, oligodeoxynucleotide (ODN) was mixed with PEI-PEG after PEG stealth or long-circulation modification on PEI (PEI-PEG), and the ODN/PEI-PEG polyelectrolyte complex had increased activity as a vector for delivery of genes into cells. ${ }^{17}$ This indicates that PEI-PEG could be useful for siRNA delivery.

In the present study, we prepared a targeted delivery system of siRNA/PEI-PEG-APRPG polyelectrolyte complexes and evaluated the efficacy of PEI-PEG-APRPG as an siRNA-delivering agent in vitro and in vivo.

\section{Materials and methods Materials}

Branched PEI, average molecular weight $25 \mathrm{kDa}$, average polymerization degree 580 , dextran fluorescein anionic (DFA, molecular weight 3000), RNase A, and diethypyrocarbonate were purchased from Sigma-Aldrich (St Louis, MO). N-hydroxysuccinimide-vinyl sulfone polyethylene glycol (NHS-PEG-VS, molecular weight 7452) and N-hydroxysuccinimide-methyl poly(ethylene glycol) (PEGNHS, molecular weight 4834) were custom synthesized by Jenkem Technology Co Ltd (Beijing, China). APRPG peptide was custom synthesized by SciLight Biotechnology (Beijing, China). Fetal bovine serum was purchased from Wuhan Sanli Biotechnology Co Ltd (Wuhan, China). Dulbecco's Modified Eagle's Medium was purchased from Tianrunshanda Biotech Co Ltd (Beijing, China). 3-(4,5-dimethylthiazol-2-yl)-2,5diphenyltetrazolium bromide (MTT) was purchased from Amresco Inc (Solon, OH). TRIzol ${ }^{\circledR}$ Reagent was obtained from Invitrogen (Carlsbad, CA). All the solutions and instruments referring to RNA were treated with $0.1 \%$ diethypyrocarbonate. All other chemicals and reagents were of analytical grade.

A siRNA targeting human VEGF (sense: $5^{\prime}$-GGAG UACCCUGAUGAGAUCdTdT-3'; antisense: 5'-GAU CUCAUCAGGGUACUCCdTdT-3') modified with an O-methyl group (2'-O-Me) used in vivo was custom synthesized by GenePharma (Shanghai, China), and the same sequence siRNA and fluorescein isothiocyanate-labeled siRNA (FITC-siRNA) used in vitro were custom synthesized by GenePharma (Shanghai, China).

\section{Synthesis and characterization of PEI-PEG and PEI-PEG-APRPG derivatives}

Two PEGylated forms of PEI were prepared, one with PEG having an APRPG peptide at its distal end (PEI-PEG-APRPG) and the other with PEG lacking the peptide (PEI-PEG).

Synthesis of PEI-PEG was carried out as follows. A sixfold molar ratio of PEG-NHS was added to PEI in $\mathrm{KH}_{2} \mathrm{PO}_{4}^{-}$ $\mathrm{NaOH}$ solution ( $50 \mathrm{mM} \mathrm{KH}_{2} \mathrm{PO}_{4}, 39.5 \mathrm{mM} \mathrm{NaOH}, \mathrm{pH} 7.4$ ) and reacted by gentle stirring for 48 hours at room temperature. The final product, PEI-PEG, was purified by dialysis (dialysis tubing with a molecular weight cutoff 8000-12,000 Da) against distilled water and lyophilized. The composition of PEI-PEG derivative was analyzed by thin-layer chromatography, Fourier transform infrared spectra ( $\mathrm{KBr}$ pellet), gel permeation chromatography, and ${ }^{1} \mathrm{H}$-nuclear magnetic resonance (NMR). ${ }^{1} \mathrm{H}-\mathrm{NMR}$ spectra were obtained on the 
JNM-AL300 FT NMR system from JEOL (Tokyo, Japan) with standard proton parameters. Chemical shifts were referenced to the solvent $\mathrm{D}_{2} \mathrm{O}$ resonance at approximately $4.7 \mathrm{ppm}$.

A heterobifunctional PEG, ie, NHS-PEG-VS, was used as a linker between the PEI and APRPG peptide, and was carried out as follows in two steps. In the first reaction step, APRPG peptide was conjugated to NHS-PEG-VS at 2:1 ( $\mathrm{mol} / \mathrm{mol})$ in anhydrous dimethyl formamide containing a 2.5-fold molar ratio of triethylamine and reacted by gentle stirring for six hours at room temperature under nitrogen. The intermediate APRPG-PEG-VS was precipitated out by cold anhydrous ether and dried. Conjugation was confirmed by matrix-assisted laser desorption/ionization time of flight mass spectral analysis (MALDI-TOF-MS) and thin-layer chromatographic analysis.

In the second step of synthesis, a 12-fold molar ratio of APRPG-PEG-VS intermediate was mixed with PEI solution in $\mathrm{KH}_{2} \mathrm{PO}_{4}-\mathrm{NaOH}$ solution ( $\mathrm{pH} 9.4$ ), and reacted by gentle stirring for 24 hours at room temperature. Completion of conjugation was confirmed by the disappearance of APRPGPEG-VS on thin-layer chromatography. The final product, PEI-PEG-APRPG, was purified by dialysis against distilled water (dialysis tubing with a molecular weight cutoff 8000-12,000 Da) and lyophilized.

The substitute degree of conjugation of PEG or APRPGPEG to PEI was determined by ${ }^{1} \mathrm{H}-\mathrm{NMR}$ spectrometry, from the ratio of the area under the peaks corresponding to the $-\mathrm{CH}_{2}-$ protons of PEI (2.8-3.1 ppm) and PEG (3.3-3.6 ppm). Different degrees of PEG substitution on PEI-PEG and PEI-PEG-APRPG polymers were prepared, and a $0.5 \%$ PEG substitution was used in the following studies.

\section{Preparation and characteristics of polyelectrolyte complex}

The siRNA was mixed with PEI, PEI-PEG, and PEI-PEGAPRPG in phosphate-buffered saline ( $\mathrm{pH}$ 7.4) at the designed nitrogen to phosphate $(\mathrm{N} / \mathrm{P})$ ratio. The siRNA complexes (siRNA/PEI, siRNA/PEI-PEG, and siRNA/PEI-PEGAPRPG) were spontaneously achieved via electrostatic interaction between cationic PEI and negative siRNA. The mixtures were then incubated for 30 minutes at room temperature.

Similarly, the DFA complexes (DFA/PEI, DFA/PEI-PEG, DFA/PEI-PEG-APRPG) were obtained by mixing DFA with PEI, PEI-PEG, and PEI-PEG-APRPG at a nitrogen to hydroxyl ratio of 4:1 in phosphate-buffered saline.
The hydrodynamic diameter and zeta potentials of freshly prepared complexes were measured using a Zetasizer Nano ZS ZEN3600 (Malvern, Worcestershire, UK) at $25^{\circ} \mathrm{C}$. Measurements were performed in phosphate-buffered saline (pH 7.4). The shapes of the siRNA/PEI-PEG complexes and naked siRNA were evaluated by transmission electron microscopy.

\section{Gel retardation assay}

The stability of naked siRNA and siRNA complexes against RNase A digestion was investigated. Aliquots of $15 \mu \mathrm{L}$ complexes corresponding to $1.33 \mu \mathrm{g}$ of siRNA were incubated in $40 \mu \mathrm{g} / \mathrm{mL}$ RNase A at $37^{\circ} \mathrm{C}$. Afterwards, an aliquot was removed from the sample at an indicated time interval and an equal volume of $1 \%$ sodium dodecyl sulfate was added to the sample, then manipulated at $65^{\circ} \mathrm{C}$ for 5 minutes, and the resulting mixtures were applied to $3 \%$ agarose gel, with electrophoresis carried out at $15 \mathrm{~mA}$ for 1 hour. The resulting gel was imaged on a Biometra transilluminator.

\section{Transfection assay and cell proliferation inhibition assay in vitro}

Human breast cancer cell line MCF-7 cells were provided by the Institute of Basic Medical Sciences Chinese Academy of Medical Sciences (Beijing, China) and grown and maintained in Dulbecco's Modified Eagle's Medium supplemented with $10 \%$ fetal bovine serum, $100 \mathrm{U} / \mathrm{mL}$ penicillin, and $100 \mu \mathrm{g} /$ $\mathrm{mL}$ streptomycin, and maintained at $37^{\circ} \mathrm{C}$ in a $5 \%$ carbon dioxide incubator.

MCF-7 cells were seeded at a density of $2 \times 10^{5}$ cells/ well in six-well cell plates and incubated at $37^{\circ} \mathrm{C}$ in a $5 \%$ carbon dioxide incubator. After 24 hours of incubation, cells achieved $80 \%$ confluency, and the media were replaced with Dulbecco's Modified Eagle's Medium containing the FITC-siRNA complexes. After 6 hours of incubation, the cells treated with FITC-siRNA complexes were lysed. FITCsiRNA was quantified using a FACS Caliber flow cytometer from Becton Dickinson (New York, NY) with a $488 \mathrm{~nm}$ excitation laser and a $525 \mathrm{~nm}$ emission filter.

MCF-7 cells were seeded in 96-well plates at a density of 8000 cells/well and incubated at $37^{\circ} \mathrm{C}$ in a $5 \%$ carbon dioxide incubator. After 24 hours of incubation, the media were replaced with Dulbecco's Modified Eagle's Medium containing the siRNA complexes (40 nM of siRNA/well) and the corresponding polymers, respectively. Following 5 hours of incubation at $37^{\circ} \mathrm{C}$, the transfection media were then removed and replaced with fresh growth medium. After 
72 hours of incubation, the media were replaced by $180 \mu \mathrm{L}$ of fresh Dulbecco's Modified Eagle's Medium (10\% fetal bovine serum) and $20 \mu \mathrm{L}$ of $5 \mathrm{mg} / \mathrm{mL}$ MTT solution and incubated further for 4 hours away from light. The media were removed and $100 \mu \mathrm{L}$ of dimethyl sulfoxide was added to the wells, and the absorbance was measured at $490 \mathrm{~nm}$ using a microplate reader. The proliferation-inhibiting ability of siRNA in the different complexes was evaluated by the difference in inhibition rate between siRNA complexes and the corresponding polymers.

\section{Tissue distribution in tumor-bearing mice}

$\mathrm{Balb} / \mathrm{C}$ nude mice ( 5 weeks of age) were obtained from the Department of Laboratory Animal Science, Peking University Health Science Center (Beijing, China) and were housed under standard conditions with free access to food and water. All of the animal experiments adhered to the principles of care and use of laboratory animals, and were approved by the Institutional Animal Care and Use Committee of Peking University. The tumor model was generated by subcutaneous injection of MCF-7 cell suspension $\left(2 \times 10^{6}\right.$ cells $)$ into the flank region of the mouse.

When the volume of the tumor reached $50 \mathrm{~mm}^{3}$, DFA complexes were administered through the tail vein at a dose of $10 \mu \mathrm{g} / \mathrm{mouse}$ and DFA alone was used as a control. After half an hour, the mice were sacrificed and the various tissues, including heart, liver, spleen, lung, kidney, and tumor, were harvested, washed with phosphate-buffered saline, and weighed. The tissues were homogenized in phosphate-buffered saline using an electric homogenizer. The tissue homogenates were centrifuged for 20 minutes at $4000 \mathrm{rpm}\left(4^{\circ} \mathrm{C}\right)$. The DFA fluorescent intensity of the tissue supernatants was detected by a fluorospectrophotometer (RF-5301PC, Shimadzu, Kyoto, Japan) at $488 \mathrm{~nm}$ and $525 \mathrm{~nm}$ of excitation and emission wavelength, respectively. The amount of DFA in each tissue was calculated by relating fluorescent intensity to the standard curve and expressed as the mean \pm standard deviation of the percentage of injected dose per gram of tissue.

\section{VEGF siRNA treatment in tumor-bearing mice}

$\mathrm{Balb} / \mathrm{C}$ nude mice (female, 4 weeks of age) were used in siRNA treatment. The tumor model was generated by subcutaneous injection of MCF-7 cell suspension $\left(2 \times 10^{6}\right.$ cells) into a flank region of the mouse to establish the tumor model. When the volume of the tumor reached $250 \mathrm{~mm}^{3}$, the siRNA complexes containing $2 \mathrm{nmol}$ siRNA were injected intravenously through the tail vein on days $1,4,8$, and 12 .
Tumor growth was monitored by a caliper to measure the major and minor axis. The respective tumor volume was determined based on the following formula: tumor volume $=($ major axis $) \times(\text { minor axis })^{2} / 2$. The relative tumor volume was used to compare the tumor growth tendency in each group based on the following formula: relative tumor volume $=$ daily tumor volume/tumor volume on first injection day.

To determine the amount of VEGF in each solid tumor region, tumors were harvested from the tumor-bearing mice on days 8 and 22 after the initial injection. The tumors were weighed and homogenized in phosphate-buffered saline using a glass-teflon homogenizer. The tissue homogenates were centrifuged for 30 minutes at $13,500 \mathrm{rpm}\left(4^{\circ} \mathrm{C}\right)$ to remove insoluble tissue debris and the supernatant was used for further analysis. The amount of protein was determined using a Bradford kit (Beyotime Institute of Biotechnology, Jiangsu, China). The amount of human VEGF produced in the tumor was determined using a human VEGF enzyme-linked immunosorbent assay kit (Boster Biological Technology, Wuhan, China) according to the manufacturer's recommendation. The quantity of intratumoral VEGF protein (ng/mg protein) was equal to the amount of VEGF protein/ the amount of protein.

To determine the intratumoral level of VEGF mRNA, total RNA was isolated from about $80 \mathrm{mg}$ of tumor tissue using TRIzol ${ }^{\circledR}$ Reagent and following the manufacturer's recommendation. The concentration of RNA was detected by ultraviolet spectrophotometer (TU-1901, Purkinje, China) at $260 \mathrm{~nm}$, and the A260/A280 ratio of 1.9-2.1 was reached when RNA was dissolved in tris-ethylenediamine tetra-acetic acid buffer ( $\mathrm{pH}$ 8.0).

Reverse transcription polymerase chain reaction was performed using a RevertAid ${ }^{\mathrm{TM}}$ First Strand cDNA synthesis kit (MBI Fermentas, Burlington, ON) and SYBR ${ }^{\circledR}$ Premix Ex Taq $^{\text {TM }}$ II (TaKaRa, Otsu, Japan). cDNA synthesis was completed according to the manufacturer's recommendation and polymerase chain reaction was carried out using an ABI Prism 7500 real-time polymerase chain reaction system under the following thermal cycling conditions: denaturation; one cycle $95^{\circ} \mathrm{C}$ for 30 seconds, polymerase chain reaction; 40 cycles at $95^{\circ} \mathrm{C}$ for 5 seconds and at $60^{\circ} \mathrm{C}$ for 34 seconds. The polymerase chain reaction primers to detect human VEGF (forward: 5'-AGGAGGGCAGAATCATCACG-3'; reverse: 5'-CAAGGCCCACAGGGATTTTCT-3') and human $\beta$-actin (forward: 5'-TGTACGCCTCTGGCCGTACC-3'; reverse: 5'-CCACGTCACACTTCATGATGG-3') were custom synthesized by AuGCT Biotechnology (Beijing, China). 
On day 22 after initial injection of the siRNA complexes and phosphate-buffered saline, the tumor-bearing mice were euthanized by cervical dislocation and the tumors were harvested for immunohistochemical staining. The vessels were marked with rabbit antimouse CD34 antibody and rabbit streptavidin-peroxidase kit (Zhongshan Goldenbridge Biotechnology, Beijing, China). The colorimetric detection of microvessels was performed using a DAB detection kit (Zhongshan Goldenbridge Biotechnology) following the manufacturer's recommendation. To determine intratumoral microvessel density, five independent areas (each microscope field is $0.100 \mathrm{~mm}^{2}$ ) were randomly selected in the hot areas, and images were obtained at a magnification of $200 \times$ under a microscope equipped with a Leica Q550CW imaging system (Somme, Germany). The microvessel density $(t=$ number of vessels $/ \mathrm{mm}^{2}$ ) was equal to the number of vessels in a microscope field/area of a microscope field.

\section{Statistical analysis}

All data are given as the mean \pm standard deviations or the mean \pm standard errors of the mean of independent measurements. Statistical analysis was performed using SPSS software (v 13.0; SPSS Inc, Chicago, IL). Statistical significance was assigned for $P$ values $<0.05$.

\section{Results}

\section{Synthesis and characterization of PEI-PEG and PEI-PEG-APRPG derivatives}

In Figure 1A, peaks at $2886 \mathrm{~cm}^{-1}$ and $1104 \mathrm{~cm}^{-1}$ were attributed to the $\mathrm{C}-\mathrm{H}$ stretching vibration of methylene and $\mathrm{C}-\mathrm{O}$ stretching vibration of the ether linkage, which demonstrated the existence of $-\mathrm{CH}_{2}-\mathrm{CH}_{2}-\mathrm{O}$ in methyl PEG. In Figure 1B, in addition to the peaks of $\mathrm{C}-\mathrm{H}$ and $\mathrm{C}-\mathrm{O}$ stretching vibration of $\mathrm{PEG}$, a new peak due to imide appeared at $1741 \mathrm{~cm}^{-1}$, demonstrating the existence of NHS and the structure of PEG-NHS. In Figure 1C, the peaks at $2941 \mathrm{~cm}^{-1}$ and $3200 \sim 3400 \mathrm{~cm}^{-1}$ (broad) were attributed to the $\mathrm{C}-\mathrm{H}$ stretching vibration of methylene and $\mathrm{N}-\mathrm{H}$ stretching vibration, which confirmed the $-\mathrm{CH}_{2}-\mathrm{CH}_{2}-\mathrm{NH}_{2}$ functional group of PEI. In Figure 1D, except for the peaks from $\mathrm{N}-\mathrm{H}$ (3200-3400 $\left.\mathrm{cm}^{-1}\right), \mathrm{C}-\mathrm{H}\left(2886 \mathrm{~cm}^{-1}\right)$, and C-O $\left(1104 \mathrm{~cm}^{-1}\right)$ stretching vibration, the peak at $1741 \mathrm{~cm}^{-1}$ disappeared, which indicated disappearance of NHS and the existence of $-\mathrm{CH}_{2}-\mathrm{CH}_{2}-\mathrm{NH}_{2}$ and $-\mathrm{CH}_{2}-\mathrm{CH}_{2}-\mathrm{O}$ functional groups. Thinlayer chromatography (TLC) also revealed that the production of PEG-PEI was completed.

In the ${ }^{1} \mathrm{H}-\mathrm{NMR}$ of PEI-PEG (Figure 2A), the signals at $\delta$ 2.5-2.8 (m) were attributed to the methylene group in PEI, the signal at $\delta 3.202$ (s) was attributed to the $\mathrm{H}_{\text {of }} \mathrm{CH}_{3}-\mathrm{O}$ and $\delta 3.5(\mathrm{~m})$ was attributed to the methylene group in PEG. The integration ratio of PEI $(\delta 2.5-2.8)$ and PEG $(\delta 3.5)$ indicated that 8.68 molar PEG had been connected to one molar PEI and the molecular weight of PEI-PEG was calculated as 66,000 .

A heterobifunctional PEG, ie, NHS-PEG-VS, was used as a linker between PEI and APRPG. In the first reaction step, the NHS group of heterobifunctional PEG was reacted with the amino terminal primary amine of a peptide that was preactivated by an excess of triethylamine in anhydrous dimethyl formamide. In the second reaction step, APRPG-PEG-VS were mixed with PEI in pH 9.4. MALDI-TOF-MS of VS-PEG-NHS and APRPG-PEG-NHS produced a broad peak centered at $7589 \mathrm{~m} / \mathrm{z}$ and $7980 \mathrm{~m} / \mathrm{z}$, and each peak was spaced by $44 \mathrm{Da}$, ie, the molecular weight of ethylene oxide monomer (Figure 3). The molecular weight increment of APRPG-PEG-NHS from VS-PEG-NHS was about $400 \mathrm{Da}$, which was in conformity with the molecular weight of APRPG peptide. This result confirmed the formation of APRPG-PEG-NHS.

The ${ }^{1} \mathrm{H}-\mathrm{NMR}$ of PEI-PEG-APRPG (Figure 2B) showed complete disappearance of the vinyl group $(\delta 6.2-6.4)$, the signals at $\delta 2.5-2.9(\mathrm{~m})$ were attributed to the methylene group in PEI, and the signal at $\delta 3.5(\mathrm{~m})$ was attributed to the methylene group in PEG. In the ${ }^{1} \mathrm{H}-\mathrm{NMR}$ of PEI-PEGAPRPG, APRPG peptide signals could not be identified easily because signals from PEI-PEG overwhelmed the APRPG peptide signals. The conjugation degree of APRPG-PEG to PEI was calculated from the integral ratio of $-\mathrm{CH}_{2}-$ protons of PEI ( $\delta 2.5-2.9)$ to PEG $(\delta 3.5)$. Based on this estimate, an average of about 15.86 APRPG-PEG molecules attached to each $25 \mathrm{kDa}$ PEI molecule, and the molecular weight of PEI-PEG-APRPG was calculated as 150,024.38 Da.

\section{Characteristics of siRNA complexes}

The size and zeta potential of the siRNA complexes were about $20-50 \mathrm{~nm}$ and about $17.2 \mathrm{mV}$ measured by Zetasizer, respectively. The particle diameter of siRNA/PEI-PEG complexes by transmission electron microscopy was $30-40 \mathrm{~nm}$, and they had a regular spheroid appearance (Figure 4).

To identify the formation of siRNA/PEI-PEG complexes, agarose gel electrophoresis was performed at different $\mathrm{N} / \mathrm{P}$ ratios, and the gel was immersed in ethidium bromide solution for 20 minutes before imaging (Figure 5). The movement of siRNA in the gel became slower as the amount of PEI-PEG increased, demonstrating that PEI-PEG bound to siRNA by neutralizing its charge. At N/P ratios exceeding the neutralization composition, the complex micelles migrated slightly toward the anode, suggesting that they had 


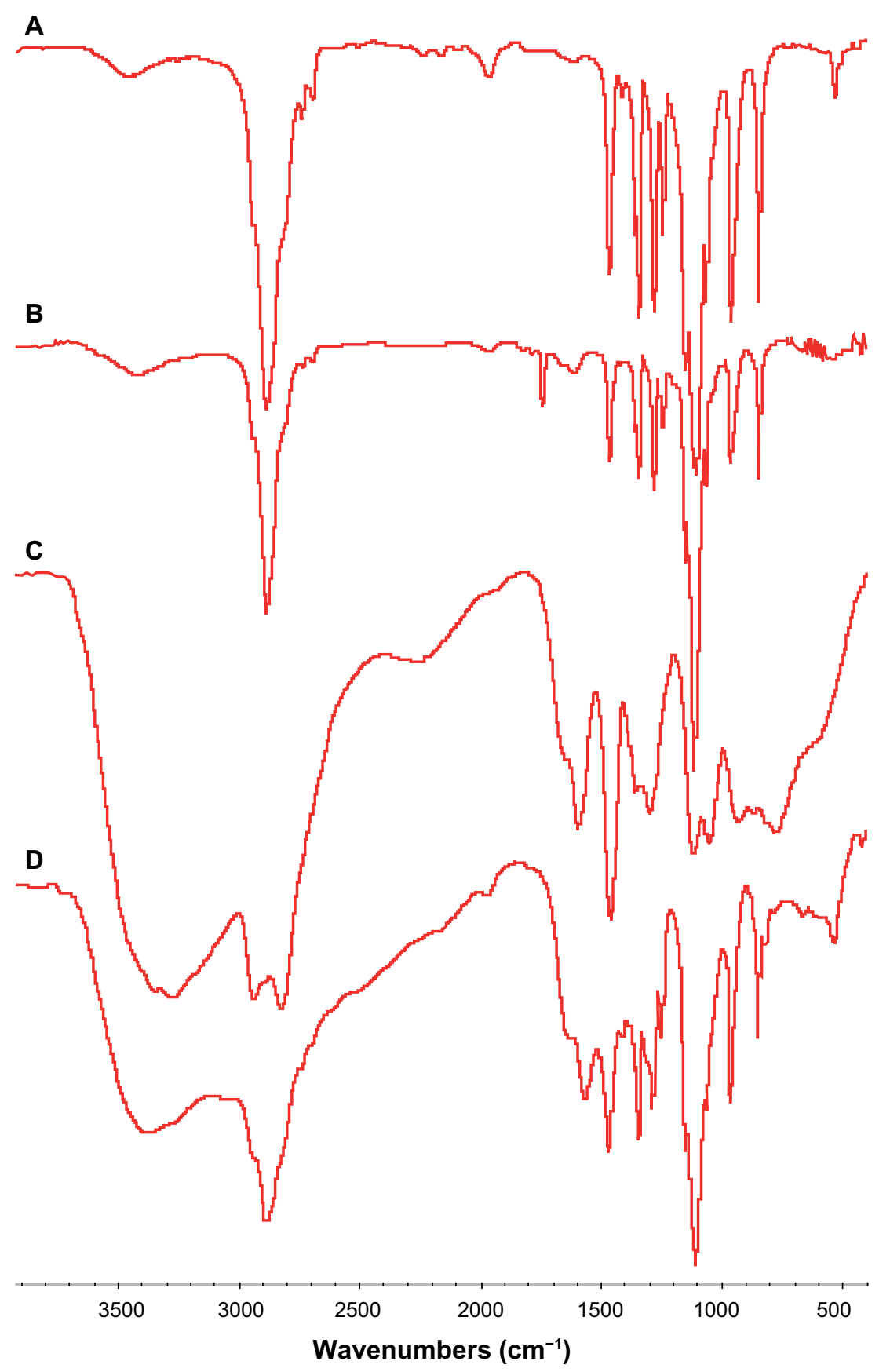

Figure I Fourier transform infrared spectra of polymers. (A) Methoxypolyethylene glycol, (B) N-hydroxysuccinimide-polyethylene glycol, (C) polyethylenimine, and (D) polyethylenimine-polyethylene glycol.

a small positive charge. Complete complex formations were achieved at an N/P ratio of approximately 10, suggesting that all negatively charged siRNA phosphate residues were saturated with PEI-PEG.

\section{Stability of siRNA/PEI-PEG complexes in RNase $A$}

To investigate the stability of siRNA/PEI-PEG complexes in the presence of RNase A, naked siRNA and siRNA/PEI-PEG complexes were incubated in $40 \mu \mathrm{g} / \mathrm{mL}$ RNase A at $37^{\circ} \mathrm{C}$. The naked siRNA showed degradation after 24 hours of incubation in the RNase A-containing medium (Figure 6A). In contrast, siRNA/PEI-PEG complexes could last for up to 36 hours without a significant loss of integrity under these conditions (Figure 6B). This result suggested that PEI-PEG could increase the stability of siRNA, which was likely due to the presence of a shell layer that sterically hinders access of nucleases to the siRNA which is set into the branch structure of PEI. 

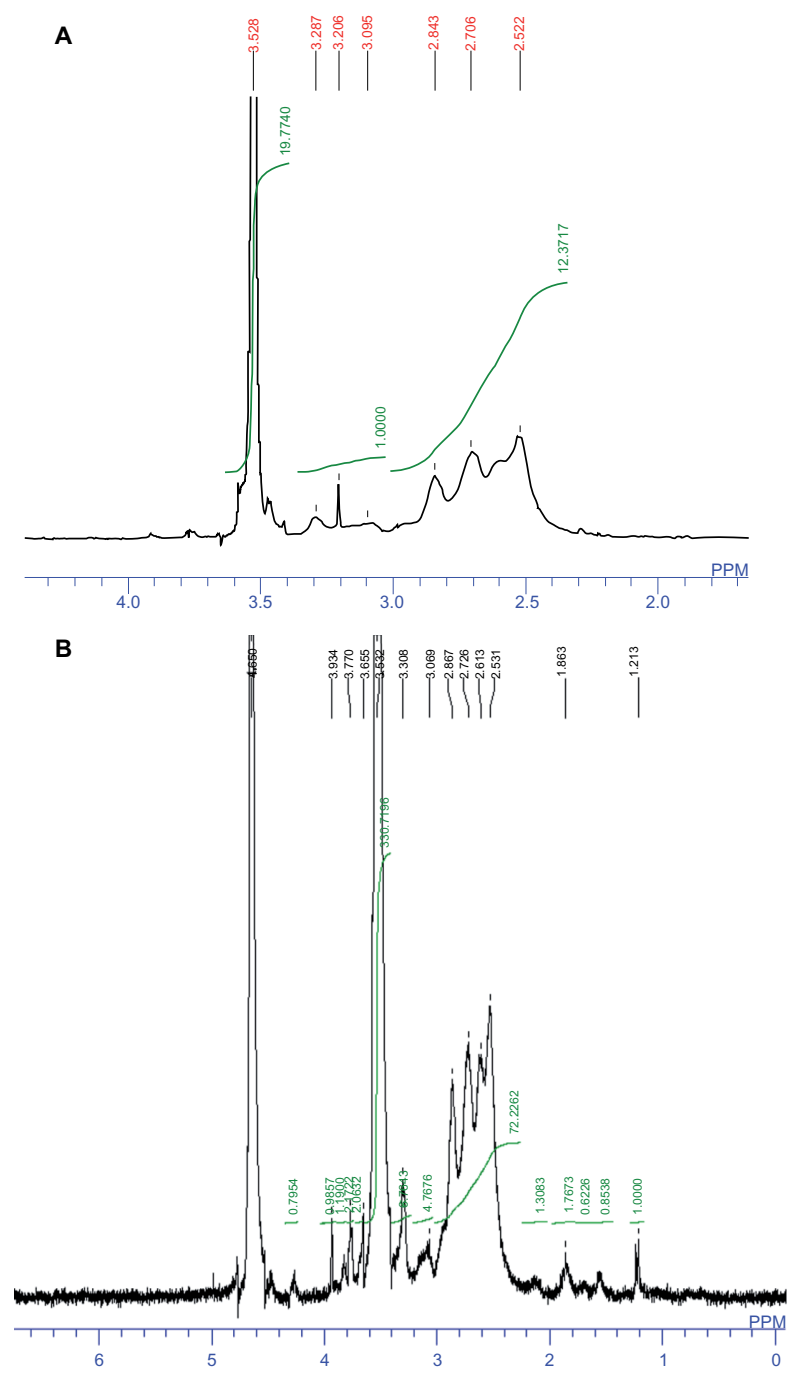

Figure 2 'H-nuclear magnetic resonance spectra of (A) polyethyleniminepolyethylene glycol and (B) polyethylenimine-polyethylene glycol-Ala-Pro-Arg-ProGly in $\mathrm{D}_{2} \mathrm{O}$. The peaks at about 2.5-2.9 and about $3.5 \mathrm{ppm}$ are attributed to polyethylenimine and methoxypolyethylene glycol, respectively.

\section{Transfection and cell proliferation inhibition assay in MCF-7 cells in vitro}

We compared the effect of different factors on the transfection efficiency of the siRNA complexes. When using Dulbecco's Modified Eagle's Medium without serum as the transfection mediator of MCF-7 cells, the transfection efficiency of the siRNA/PEI complexes was low, but the transfection efficiency of the siRNA/PEI-PEG and siRNA/PEI-PEGAPRPG complexes was relatively high (Figure 7A).

In the cell proliferation inhibition assay, we investigated the inhibitory effect of the polymers using a series of different concentrations. The results showed that polymers in the range of experimental concentrations had no cytotoxicity (data not shown). Based on this, we detected the inhibitory interaction between siRNA complexes and the corresponding polymers, and evaluated the proliferation-inhibiting ability of siRNA in the different complexes by the difference in inhibition rate. The inhibiting proliferation ability of siRNA complexes was as follows: siRNA/PEI-PEG-APRPG $>$ siRNA/PEIPEG $>$ siRNA/PEI, and there was a significant difference between the siRNA/PEI and siRNA/PEI-PEG-APRPG complexes $(P<0.05$, Figure $7 \mathrm{~B})$ at an N/P of 100 and a siRNA concentration of $40 \mathrm{nM}$.

\section{Tissue distribution in tumor-bearing mice}

DFA and siRNA both have anionic groups which can associate with cationic groups of PEI through electrostatic interaction. To design an effective formulation for nucleic acids and peptides containing multiple-charged groups, DFA was used as a model multiple-charged compound and combined with cationic lipids, and these complexes were wrapped with neutral lipids. ${ }^{18}$ Our investigations of the tissue distribution of PEI derivatives were conducted using DFA as a model multiply-charged compound because of its satisfactory stability and adequate fluorescence. Figure 8 shows the tissue distribution of DFA in MCF-7 tumor-bearing mice. Compared with DFA, the amount of DFA complexes (DFA/PEI, DFA/PEI-PEG, and DFA/PEIPEG-APRPG) were a little smaller in the heart and lung, but higher in the spleen, liver, kidney, and tumor tissue. In the liver, there was a significant difference $(P<0.01)$ between the uptake of DFA alone and the DFA complexes (DFA/ PEI-PEG-APRPG, DFA/PEI-PEG, and DFA/PEI). The major pathway for the removal of these nanoscale complexes from the blood appeared to be capture in the mononuclear phagocyte system, especially in the liver. ${ }^{19}$ DFA could be rapidly eliminated in the kidney, ${ }^{20}$ and the higher amount of DFA complexes (DFA/PEI, DFA/PEI-PEG, and DFA/PEIPEG-APRPG) in the kidney suggests that the PEI derivatives can prevent the drug from being eliminated in some extent. However, the amount of drug in some of the normal organs was more than that in the tumor cells. The significantly $(P<0.05)$ higher amount of DFA/PEI-PEG-APRPG than DFA, DFA/PEI and DFA/PEI-PEG in the tumor cells suggests that, when modified with APRPG peptide, these complexes could enhance target accumulation in the tumor. APRPG only adheres to neovascular endothelial cells, which limits access to normal cells.

\section{VEGF siRNA treatment in tumor-bearing mice}

To investigate the effect of siRNA treatment, the tumor size was investigated every 3 days after the initial injection. 

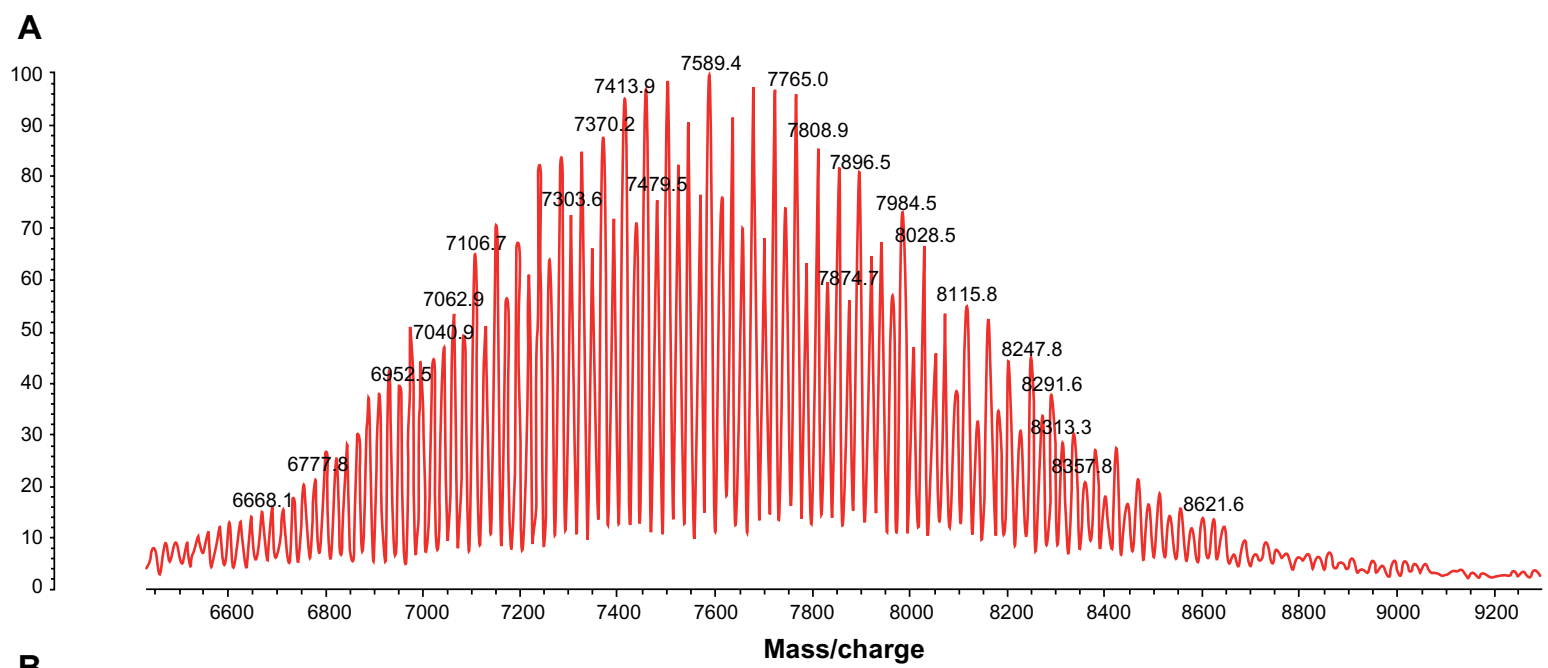

B

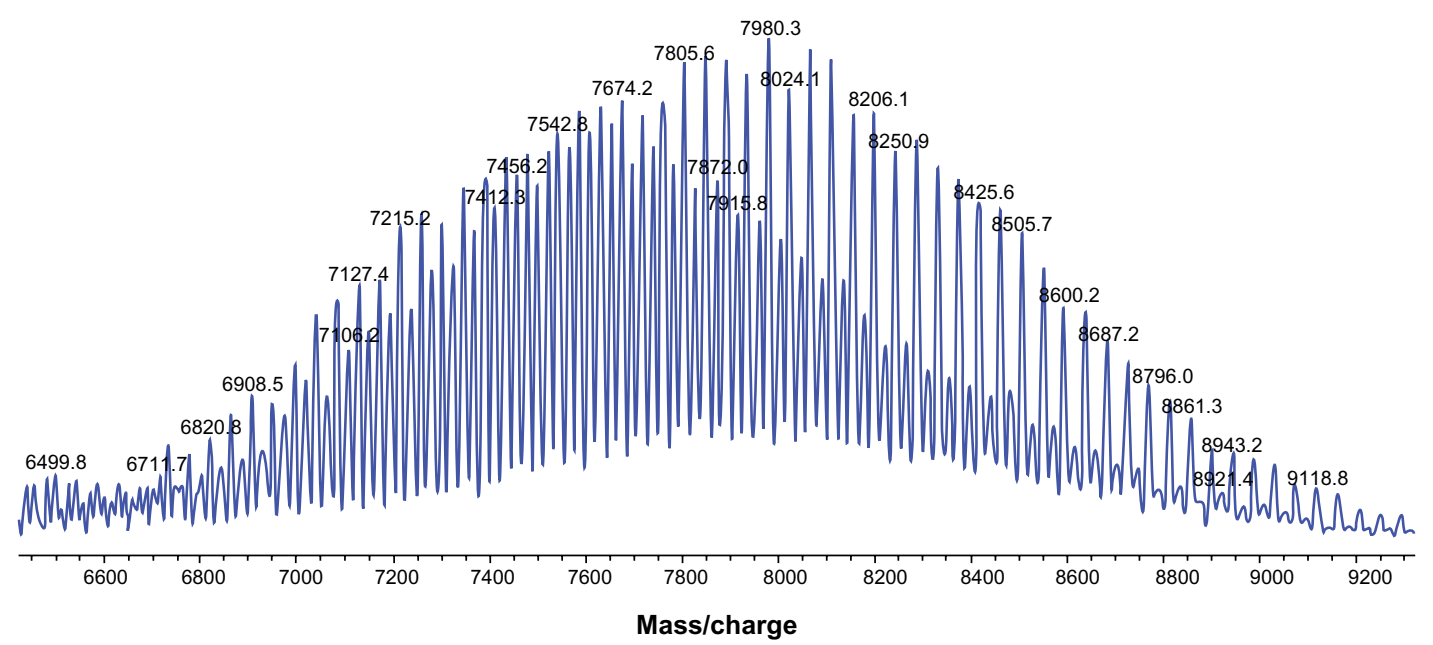

Figure 3 (A) Flight mass spectral (MALDI-TOF-MS) analysis of N-hydroxysuccinimide-vinyl sulfone-polyethylene glycol and (B) Ala-Pro-Arg-Pro-Gly-vinyl sulfone-polyethylene glycol.

Relative tumor volume was used to detect the different effects (Figure 9A). The results showed that the tumor treated with phosphate-buffered saline had the most rapid growth rate. The siRNA complexes (siRNA/PEI and siRNA/PEIPEG-APRPG) had a stronger tumor inhibition effect than the siRNA. The tumor volumes were significantly different
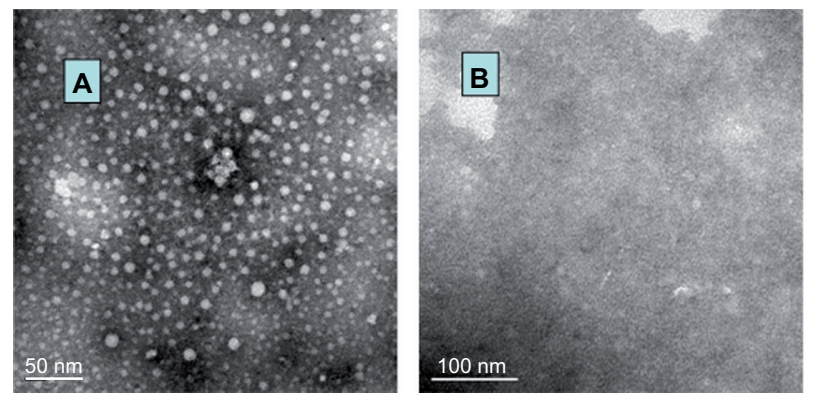

Figure 4 Transmission electron microscope images for (A) small interfering RNA/ polyethylenimine-polyethylene glycol complexes and (B) naked small interfering RNA solution in phosphate-buffered saline (7.4). for siRNA/PEI-PEG-APRPG complexes $(P<0.01)$ and siRNA/PEI complexes $(P<0.05)$ compared with phosphatebuffered saline on day 7 after two injections. Afterwards, the siRNA group had a significant difference compared with phosphate-buffered saline $(P<0.05)$, occurring on day 10 after three siRNA injections. The siRNA/PEI-PEG-APRPG complexes showed highest inhibition of tumor growth.

Immunohistochemical staining of tumor-associated microvessels showed a relationship between suppression of VEGF expression and intratumoral neovascularization. The higher the microvessel density, the worse the inhibiting effect. On day 22 after the initial injection, the tumors were harvested for immunohistochemical staining to observe neovascularization. The microvessel density quantified by number of microvessels per unit area showed the effects of the different formulations (Figure 9B). The mean value of microvessel density for siRNA/PEI-PEG-APRPG, siRNA/ PEI, and siRNA showed a significant decline compared with 


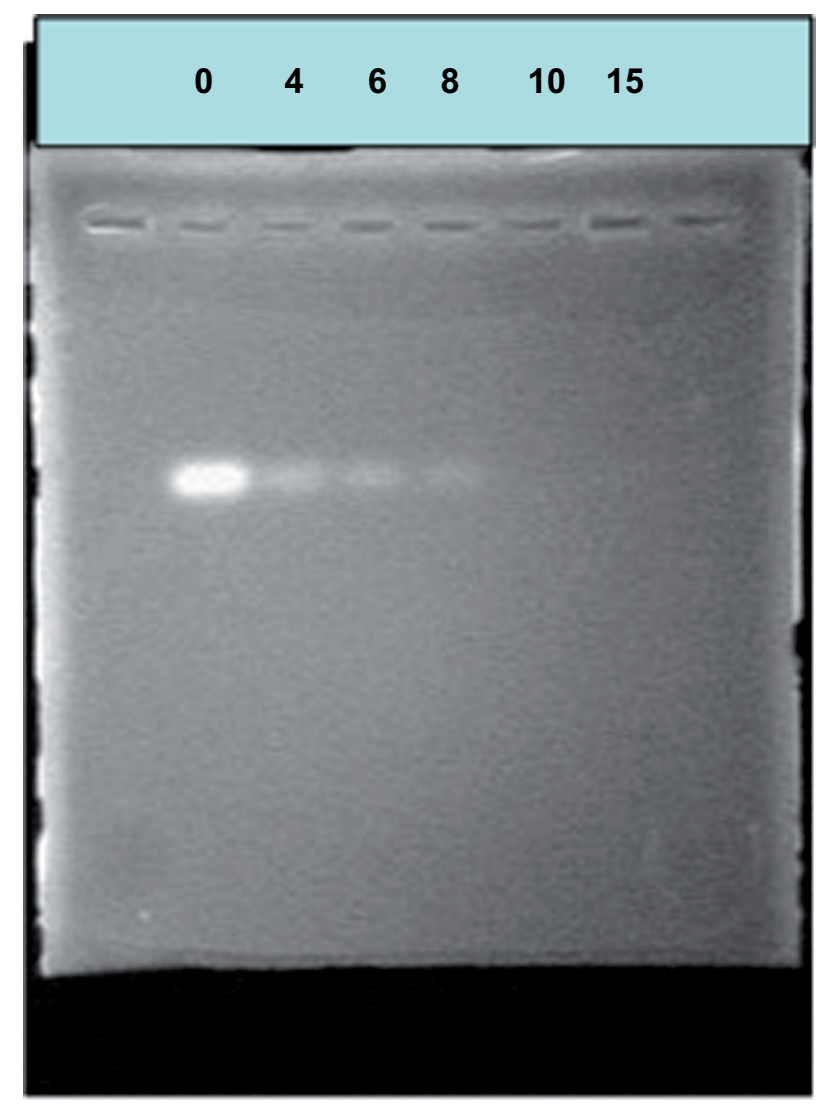

Figure 5 Agarose electrophoresis of small interfering RNA/polyethyleniminepolyethylene glycol complexes.

that in the phosphate-buffered saline group $(P<0.05)$. The results suggest that VEGF siRNAs had an inhibitory effect on microvessel formation. Specimens treated with siRNA/ PEI-PEG-APRPG complexes showed the greatest inhibitory effect in mean value of microvessel density.

The level of VEGF could express the gene silence effect of VEGF siRNA. There was significant inhibition for siRNA/ PEI-PEG-APRPG complexes, siRNA/PEI complexes, and
siRNA on day 22 after the initial injection, and the siRNA/ PEI-PEG-APRPG complexes had the most inhibiting effect on the expression of VEGF protein (Figure 9C).

The VEGF mRNA in tumors was detected by the reverse transcription polymerase chain reaction. The data were analyzed by the $2^{-\Delta \Delta C t}$ method. The higher the value, the more the VEGF mRNA. The siRNA/PEI-PEG-APRPG complexes showed the lowest level of VEGF mRNA on days 8 and 22 after injection (Figure 9D), and there was a significant difference between the siRNA/PEI-PEG-APRPG complexes and siRNA alone. This suggests that the PEIPEG-APRPG carrier could deliver siRNA efficiently to the tumor in which siRNA expresses a gene silence effect and reduces the level of mRNA. Comparing the results from day 8 and day 22, we found that on day 8 (two injections, 4 days after the last injection) the mRNA level was significantly different $(P<0.05)$ between siRNA/PEI-PEG-APRPG and siRNA, but on day 22 (four injections, 10 days after the last injection) there was no significant difference. The silencing effect is decreased with the passage of time. This indicates the importance of multiple injections of siRNA.

\section{Discussion}

Suppression of VEGF gene expression is an important factor in tumor growth and regulates tumor angiogenesis, representing a novel approach to cancer treatment. The MCF-7 cell line is a type of human breast carcinoma overexpressing VEGF, leading to increased tumor angiogenesis. siRNA has become a major strategy in gene therapy. VEGF siRNA can degrade homologic mRNA by forming an RNA-induced silencing complex with other cellular proteins. ${ }^{21}$ There are some challenges using siRNA therapy, ie, "off-target" effects, immune stimulation, and delivery issues, ${ }^{22}$ the latter being the most important. Naked siRNA has poor intracellular uptake, limited blood stability,
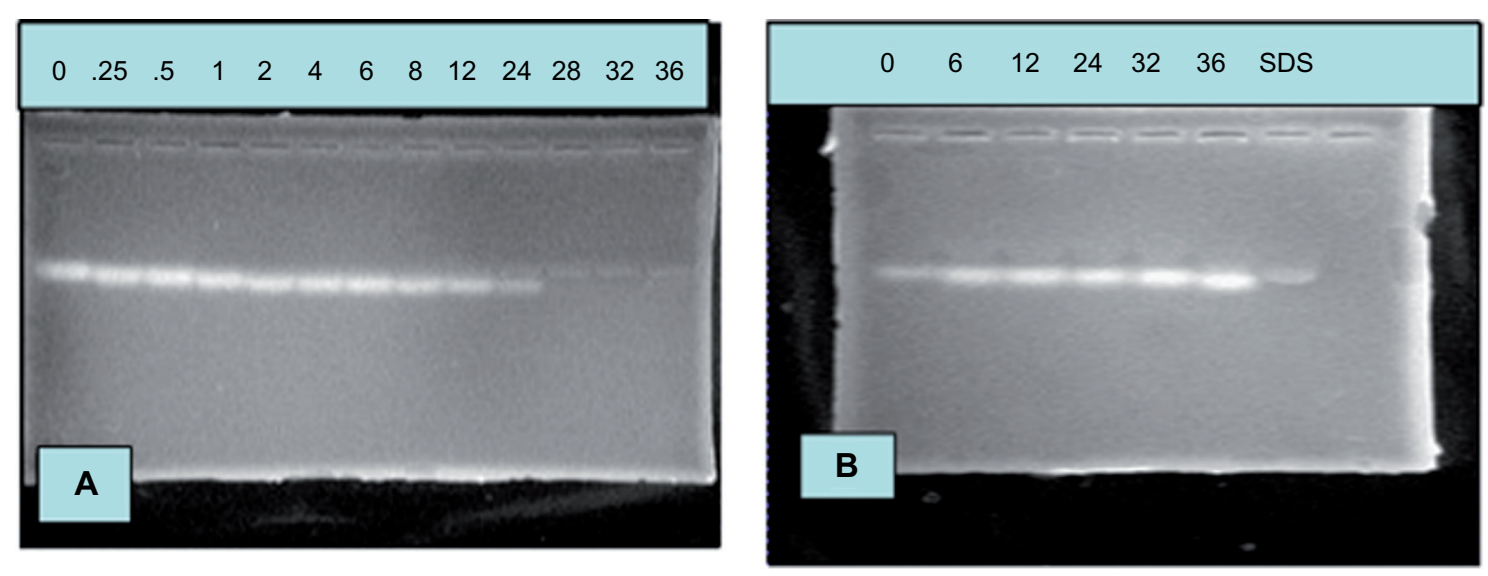

Figure 6 Stability of (A) naked small interfering RNA and (B) small interfering RNA/polyethylenimine-polyethylene glycol complexes against RNase A digestion. 
A

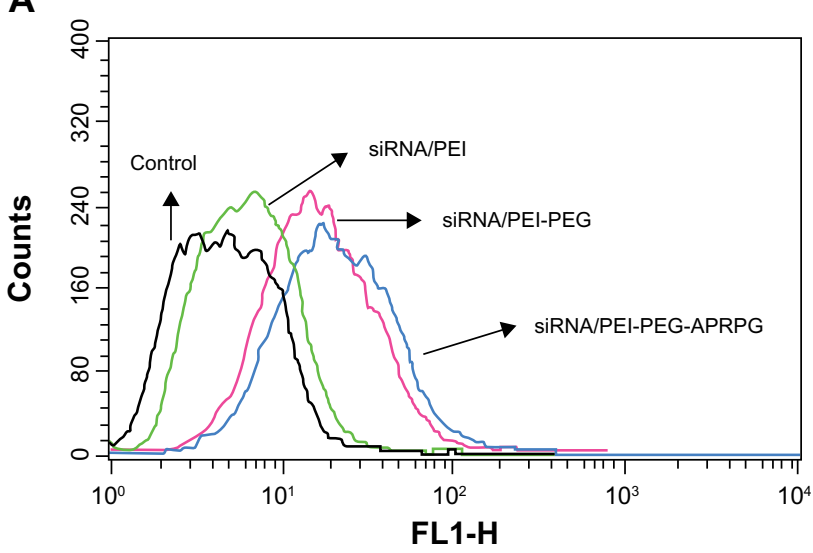

B

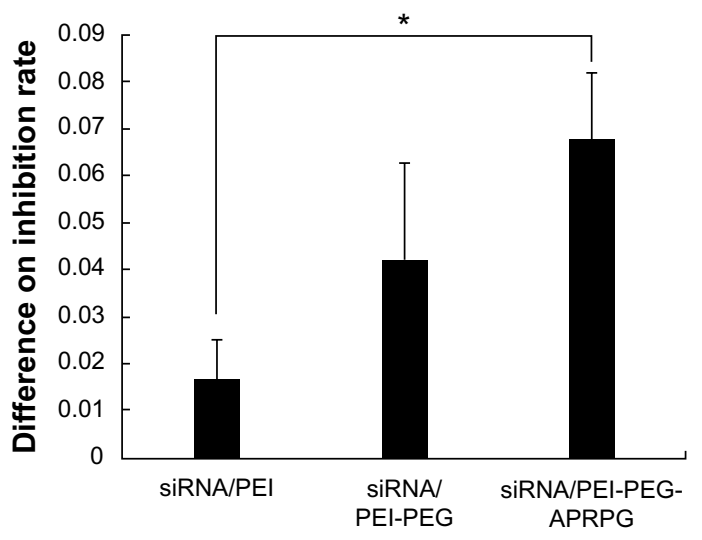

Figure 7 (A) Transfection efficiency and (B) proliferation inhibition of small interfering RNA complexes on MCF-7 cells.

Note: $* P<0.05$.

and nonspecific immune stimulation. To solve these problems, modified siRNA, cationic carriers and ligand-targeting have been used in this type of vector delivery.

Cationic polymers assemble simply with negatively charged siRNA by electrostatic interactions and protect siRNA from RNase degradation. PEI has high transfection efficiency which is attributable to the large number of $\mathrm{NH}_{2}$ on the surface and "proton sponge effect", which enables it to escape from the low $\mathrm{pH}$ of the endosome and release siRNA into the cytoplasm. The positive net charge of the complexes inhibits their aggregation due to electrostatic repulsion and improves their interaction with negatively charged extracellular matrix components and thus their cellular uptake. ${ }^{23}$

Proper modification, such as PEGylation, can decrease the toxicity ${ }^{24}$ and increase the transfection efficiency of PEI in vitro. ${ }^{25} \mathrm{PEG}$ has unique qualities, including high solubility, and lack of toxicity and immunogenicity. PEGylation is used to improve stability, solubility, and bioavailability. ${ }^{26}$ Cancer

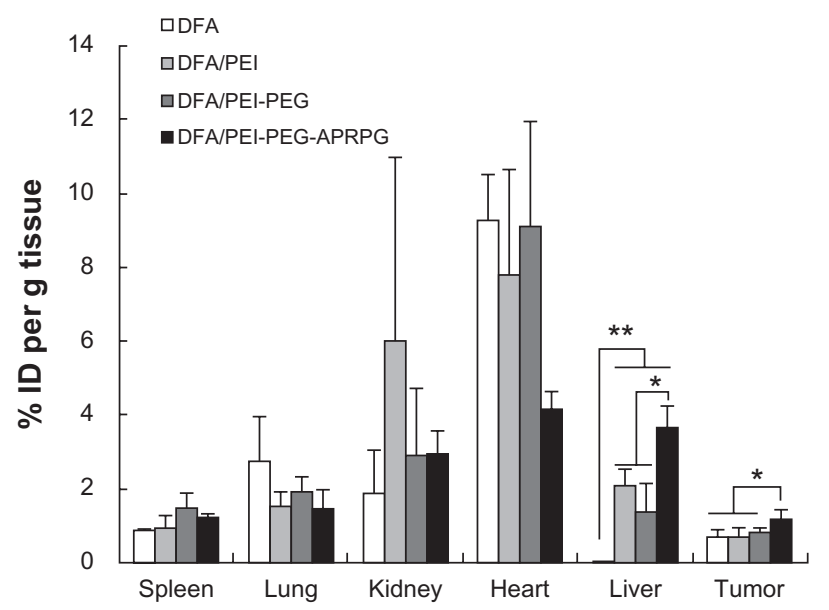

Figure 8 Tissue distribution of dextran fluorescein anionic and dextran fluorescein anionic complexes (dextran fluorescein anionic/polyethylenimine, dextran fluorescein anionic/polyethylenimine-polyethylene glycol and dextran fluorescein anionic/ polyethylenimine-polyethylene glycol-Ala-Pro-Arg-Pro-Gly) in MCF-7 tumor-bearing mice. The results are the means \pm standard deviation $(n=3-4)$.

Notes: $* P<0.01$ and $* * P<0.05$.

therapy requires high efficiency and specificity. Active targeting via antibodies and peptides achieves more selective drug delivery to tumor tissues. APRPG peptide used as an angiogenic vessel-homing peptide could selectively target tumor neovasculature. ${ }^{12,27}$ In our study, PEI-PEG-APRPG was developed by incorporating APRPG peptide into PEI via a NHS-PEG-VS spacer.

PEI-PEG and PEI-PEG-APRPG combined with siRNA showed higher transfection efficiency than PEI (Figure 7A), and improved the cell proliferation-inhibiting effect of siRNA compared with PEI (Figure 7B). DFA/PEI-PEG showed more accumulation than DFA/PEI in all the tissues except for the liver and kidney (Figure 8) in vivo. This suggests that PEGylation can enhance the retention time of the drug and target the tumor by the enhanced permeability and retention effect. The higher transfection efficiency and stronger cell proliferationinhibiting effect of siRNA/PEI-PEG-APRPG complexes in vitro, and more accumulation of DFA/PEI-PEG-APRPG complexes in tumor in vivo compared with that of siRNA/ PEI-PEG and DFA/PEI-PEG complexes demonstrates the targeting efficacy of the vessel-homing APRPG peptide. Meanwhile, siRNA/PEI-PEG-APRPG complexes reduce the tumor growth rate, density of microvessels, VEGF production, and VEGF mRNA in vivo, demonstrating that, when comodified with PEGylation and APRPG, PEI can enhance the gene silence effect. In summary, PEI-PEG-APRPG is a promising strategy for delivery of siRNA to tumor tissues by enhanced passive targeting with the enhanced retention and permeation effect (via PEGylation), as well as active 

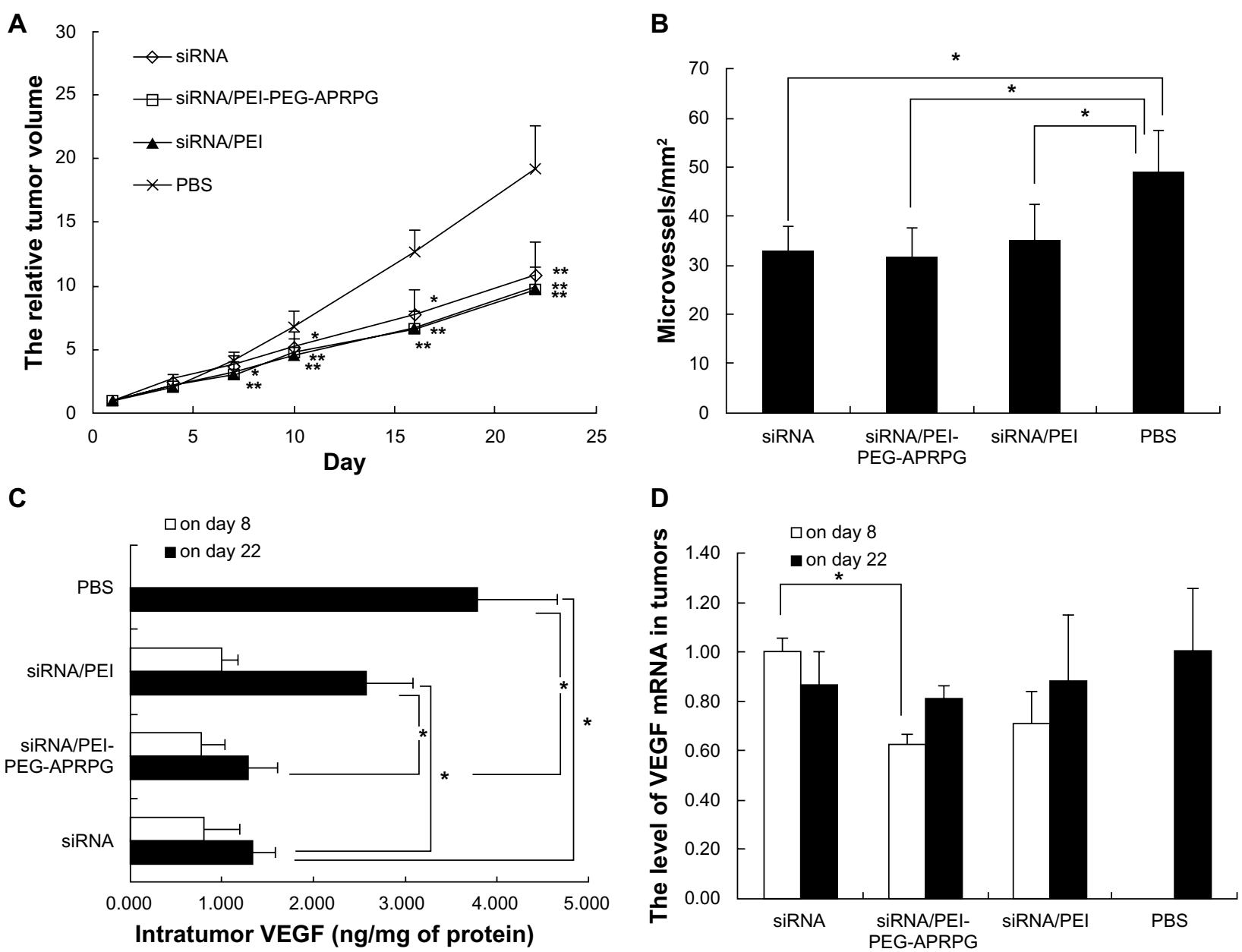

Figure 9 Antiangiogenic effect of small interfering RNAs in MCF-7 tumor-bearing mice. The small interfering RNA concentration was $10 \mu M$ and the small interfering RNA complexes were prepared at a N/P ratio of 10 in phosphate-buffered saline. $(\mathbf{A})$ Antitumor effect. The results indicate the mean \pm standard deviation $(\mathrm{n}=5-9)$. $* P<0.05$ and $* * P<0.01$ for small interfering RNA treatment groups compared with phosphate-buffered saline group, respectively. (B) Microvessel density. Each column represents the mean \pm standard deviation $(n=3-4)$. $* P<0.05$. (C) and $(D)$ Intratumor vascular endothelial growth factor production and vascular endothelial growth factor mRNA. The results represent the mean \pm standard error of the mean (on day $8, n=3$ per group; on day $22, n=5$ per group, and $n=10$ in the phosphate-buffered saline group). On day 8 small interfering RNA was used as the control and on day 22 phosphate-buffered saline was used as the control. $* P<0.05$.

targeting to the tumor angiogenic vasculature (via conjugation of the targeting moiety APRPG peptide).

Our results are similar to those previously reported by other investigators. APRPG-PEG-Lip-SU1498 was shown to inhibit VEGF-stimulated endothelial cell proliferation in vitro, significantly decrease tumor microvessel density in colon 26 NL-17 cell-bearing mice, and prolong the survival time of these mice. ${ }^{13}$ In addition to APRPG peptide, other active targeting methods have also shown a good effect for the delivery of drugs. RGD peptide which targets integrin expression and is upregulated at neovasculature sites has been reported to be a nanoparticle ligand which can selectively deliver siRNA to tumor tissue. ${ }^{28}$ Murase et al reported that dual-targeting liposomes modified with APRPG peptide and Gly-Asn-Gly-Arg-Gly peptides containing doxorubicin strongly suppressed tumor growth in colon 26 NL-17 carcinoma-bearing mice. ${ }^{29}$

Naked siRNA is rapidly eliminated by liver and kidney after intravenous administration, and chemically modified siRNA has been proposed to improve nuclease resistance and uptake by target cells. Other researchers have also identified that replacement of the phosphodiester group with a phosphothioate group at the $3^{\prime}$-end and modification with an O-methyl group ( $\left.2^{\prime}-\mathrm{O}-\mathrm{Me}\right)$ or a fluoro (2'-F) group resulted in a prolonged half-life and RNA inhibitor activity in cultured cells. ${ }^{30,31}$ Furthermore, chemically modified siRNA could reduce "off-target" transcript silencing. ${ }^{32}$ 2'-O-modified RNAs could improve their stability against hydrolysis by nucleases, extend the duration of effects, eliminate dsRNA-induced inflammatory responses, and 
enhance their hybridization affinity for the target RNAs. ${ }^{33-35}$ They enhance the half-life of siRNA in serum, suggesting that these modifications can enhance the pharmacokinetic properties, knockdown activity of siRNAs, and be suitable for potential therapeutic application of synthetic siRNAs in vivo. $^{36,37}$ We used 2'-O-Me-modified siRNA in vivo. Our results show that this kind of siRNA has an efficient silencing effect, inhibits tumor growth, reduces the number of microvessels, and suppresses the expression of VEGF protein (Figures 9A-C).

Tumor inhibition and gene silencing were observed in mice treated with two or four intravenous injections containing $54 \mu \mathrm{g}$ or $108 \mu \mathrm{g}$ of siRNA formulated in PEI. This dose corresponds to approximately $3 \mathrm{mg} / \mathrm{kg}$, which is relatively low compared with the doses used in other studies demonstrating siRNA efficacy in vivo. ${ }^{33,38-40}$ Nevertheless, the PEI formulation was also shown to facilitate delivery of siRNA to tumor tissue.

The expression of mRNA injected with siRNA/PEI complexes was lower than for siRNA (Figure 9D) as opposed to the level of VEGF protein shown in Figure 9C. The reason may be the tumor mRNA elimination rate was not synchronized with the expression of VEGF protein. In addition, siRNA is known to have an immunostimulatory effect on interferon alpha, which can downregulate the expression of VEGF and exhibits antitumor activity by an antiangiogenesis mechanism. ${ }^{41}$ This may be one reason for the difference between the levels of VEGF and mRNA.

siRNA cannot completely inhibit the expression of VEGF in MCF-7 cells, and the formation of tumor vessels is regulated by many cell factors. Single VEGF inhibition could not completely suppress angiogenesis and tumor growth. Furthermore, the effect of siRNA is temporary. Different effects of siRNAs or other drugs should be combined in cancer therapy using multiple tumor inhibition pathways.

\section{Conclusion}

We investigated a tumor-targeted system whereby PEI-PEGAPRPG was used to deliver siRNA in vitro and in vivo. Treatment with VEGF siRNA complexes had an inhibitory effect on cell proliferation and tumor growth. The complexes suppressed the increasing volume of the tumors, inhibited the formation of microvessels, and reduced the expression of VEGF protein and mRNA. The siRNA/PEI-PEG-APRPG complexes provided more efficient antiangiogenic therapy than siRNA/PEI and siRNA. This research shows that APRPG peptide as a target substance with PEG-PEI may improve siRNA delivery. It also supports gene therapy as a method to overcome the difficulty of siRNA delivery to the target site. The PEI-PEG-APRPG complex may be a useful nonviral gene vector for cancer therapy.

\section{Acknowledgments}

This work was supported by the National Natural Science Foundation of China (No. 30772665 and 30970785), National Basic Research Program of China (2007CB935801), and the Doctoral Foundation of the Ministry of Education of China (No. 20100001110056).

\section{Disclosure}

The authors report no conflicts of interest in this work.

\section{References}

1. Fire A, Xu S, Montgomery MK, et al. Potent and specific genetic interference by double-stranded RNA in Caenorhabditis elegans. Nature. 1998;391(6669):806-811.

2. Kim DH, Rossi JJ. Strategies for silencing human disease using RNA interference. Nat Rev Genet. 2007;8(3):173-184.

3. Tijsterman M, Ketting RF, Plasterk RH. The genetics of RNA silencing. Annu Rev Genet. 2002;36:489-519.

4. Bumcrot D, Manoharan M, Koteliansky V, Sah DW. RNAi therapeutics: a potential new class of pharmaceutical drugs. Nat Chem Biol. 2006; 2(12):711-719.

5. Carmeliet P. Angiogenesis in life, disease and medicine. Nature. 2005; 438(7070):932-936.

6. Ausprunk DH, Folkman J. Migration and proliferation of endothelial cells in preformed and newly formed blood vessels during tumor angiogenesis. Microvasc Res. 1977;14(1):53-65.

7. Folkman J. How is blood vessel growth regulated in normal and neoplastic tissue? G.H.A. Clowes Memorial Award Lecture. Cancer Res. 1986;46(2):467-473.

8. Hahnfeldt P, Panigrahy D, Folkman J, Hlatky L. Tumor development under angiogenic signaling: a dynamical theory of tumor growth, treatment response, and postvascular dormancy. Cancer Res. 1999; 59(19):4770-4775.

9. Kim WJ, Yockman JW, Lee M, et al. Soluble Flt-1 gene delivery using PEI-g-PEG-RGD conjugate for anti-angiogenesis. J Control Release. 2005;106(1-2):224-234.

10. Siemeister G, Martiny-Baron G, Marme D. The pivotal role of VEGF in tumor angiogenesis: Molecular facts and therapeutic opportunities. Cancer Metastasis Rev. 1998;17(2):241-248.

11. Takei Y, Kadomatsu K, Yuzawa Y, Matsuo S, Muramatsu T. A small interfering RNA targeting vascular endothelial growth factor as cancer therapeutics. Cancer Res. 2004;64(10):3365-3370.

12. Oku N, Asai T, Watanabe K, et al. Anti-neovascular therapy using novel peptides homing to angiogenic vessels. Oncogene. 2002;21(17): 2662-2669.

13. Katanasaka Y, Ida T, Asai T, et al. Effective delivery of an angiogenesis inhibitor by neovessel-targeted liposomes. Int J Pharm. 2008; 360(1-2):219-224.

14. Maeda N, Takeuchi Y, Takada M, et al. Anti-neovascular therapy by use of tumor neovasculature-targeted long-circulating liposome. J Control Release. 2004;100(1):41-52.

15. Asai T, Shimizu K, Kondo M, et al. Anti-neovascular therapy by liposomal DPP-CNDAC targeted to angiogenic vessels. FEBS Letters. 2002;520(1-3):167-170.

16. Kim SH, Jeong JH, Lee SH, Kim SW, Park TG. Local and systemic delivery of VEGF siRNA using polyelectrolyte complex micelles for effective treatment of cancer. J Control Release. 2008;129(2): 107-116. 
17. Liu LT, Qi XR. Effect of poly(ethylene glycol) modified polyethylenimine polyelectrolyte complex on pharmaceutical characteristics and uptake on breast cancer cell. J Chin Pharm Sci. 2008;17(4): 291-296.

18. Yamauchi M, Kusano H, Saito E, et al. Development of wrapped liposomes: novel liposomes comprised of polyanion drug and cationic lipid complexes wrapped with neutral lipids. Biochim Biophys Acta. 2006;1758(1):90-97.

19. Aillon KL, Xie Y, El-Gendy N, Berkland CJ, Forrest ML. Effects of nanomaterial physicochemical properties on in vivo toxicity. Adv Drug Deliv Rev. 2009; 61(6):457-66.

20. Mehvar R, Shepard TL. Molecular-weight-dependent pharmacokinetics of fluorescein-labeled dextrans in rats. J Pharm Sci. 1992;81(9): 908-912.

21. Lu PY, Xie FY, Woodle MC. siRNA-mediated antitumorigenesis for drug target validation and therapeutics. Curr Opin Mol Ther. 2003;5(3): 225-234.

22. Oh YK, Park TG. siRNA delivery systems for cancer treatment. $A d v$ Drug Deliv Rev. 2009;61(10):850-862.

23. Oh YK, Suh D, Kim JM, et al. Polyethylenimine-mediated cellular uptake, nucleus trafficking and expression of cytokine plasmid DNA. Gene Ther. 2002;9(23):1627-1632.

24. Zhang S, Kucharski C, Doschak MR, Sebald W, Uludag H. Polyethylenimine-PEG coated albumin nanoparticles for BMP-2 delivery. Biomaterials. 2010;31(5):952-963.

25. Liang B, He ML, Xiao ZP, et al. Synthesis and characterization of folate-PEG-grafted-hyperbranched-PEI for tumor-targeted gene delivery. Biochem Biophys Res Commun. 2008;367(4):874-880.

26. Veronese FM, Pasut G. PEGylation, successful approach to drug delivery. Drug Discov Today. 2005;10(21):1451-1458.

27. Maeda N, Miyazawa S, Shimizu K, et al. Enhancement of anticancer activity in antineovascular therapy is based on the intratumoral distribution of the active targeting carrier for anticancer drugs. Biol Pharm Bull. 2006;29(9):1936-1940.

28. Schiffelers RM, Ansari A, Xu J, et al. Cancer siRNA therapy by tumor selective delivery with ligand-targeted sterically stabilized nanoparticle. Nucleic Acids Res. 2004;32(19):e149.
29. Murase Y, Asai T, Katanasaka Y, et al. A novel DDS strategy, "dual-targeting", and its application for antineovascular therapy. Cancer Lett. 2010;287(2):165-171.

30. Chiu YL, Rana TM. siRNA function in RNAi: a chemical modification analysis. $R N A$. 2003;9(9):1034-1048.

31. Layzer JM, McCaffrey AP, Tanner AK, et al. In vivo activity of nuclease-resistant siRNAs. RNA. 2004;10(5):766-771.

32. Jackson AL, Burchard J, Leake D, et al. Position-specific chemical modification of siRNAs reduces "off-target" transcript silencing. RNA 2006;12(7):1197-1205.

33. Morrissey DV, Lockridge JA, Shaw L, et al. Potent and persistent in vivo anti-HBV activity of chemically modified siRNAs. Nat Biotechnol. 2005;23(8):1002-1007.

34. Freier SM, Altmann KH. The ups and downs of nucleic acid duplex stability: structure-stability studies on chemically-modified DNA:RNA duplexes. Nucleic Acids Res. 1997;25(22):4429-4443.

35. Sioud M, Furset G, Cekaite L. Suppression of immunostimulatory siRNA-driven innate immune activation by 2'-modified RNAs. Biochem Biophys Res Commun. 2007;361(1):122-126.

36. Odadzic D, Bramsen JB, Smicius R, et al. Synthesis of 2'-O-modified adenosine building blocks and application for RNA interference. Bioorg Med Chem. 2008;16(1):518-529.

37. Czauderna F, Fechtner M, Dames S, et al. Structural variations and stabilising modifications of synthetic siRNAs in mammalian cells. Nucleic Acids Res. 2003;31(11):2705-2716.

38. Ge Q, Filip L, Bai A, et al. Inhibition of influenza virus production in virus-infected mice by RNA interference. Proc Natl Acad Sci U S A 2004;101(23):8676-8681.

39. Morrissey DV, Blanchard K, Shaw L, et al. Activity of stabilized short interfering RNA in a mouse model of hepatitis B virus replication. Hepatology. 2005;41(6):1349-1356.

40. Soutschek J, Akinc A, Bramlage B, et al. Therapeutic silencing of an endogenous gene by systemic administration of modified siRNAs. Nature. 2004;432(7014):173-178.

41. Wu WZ, Sun HC, Shen YF, et al. Interferon alpha 2a down-regulates VEGF expression through PI3 kinase and MAP kinase signaling pathways. J Cancer Res Clin Oncol. 2005;131(3):169-178.
International Journal of Nanomedicine

\section{Publish your work in this journal}

The International Journal of Nanomedicine is an international, peerreviewed journal focusing on the application of nanotechnology in diagnostics, therapeutics, and drug delivery systems throughout the biomedical field. This journal is indexed on PubMed Central,

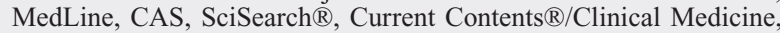

\section{Dovepress}

Journal Citation Reports/Science Edition, EMBase, Scopus and the Elsevier Bibliographic databases. The manuscript management system is completely online and includes a very quick and fair peer-review system, which is all easy to use. Visit http://www.dovepress.com/ testimonials.php to read real quotes from published authors. 